\title{
Sentimentos VASTOS: LIMINARIDADE E FOCO NARRATIVO NA LITERATURA BRASILEIRA CONTEMPORÂNEA
}

\author{
Gabriela Ruggiero Nor* \\ Universidade de São Paulo
}

\begin{abstract}
Resumo
As obras Rútilo nada, de Hilda Hilst, Teatro, de Bernardo Carvalho e Acenos e afagos, de João Gilberto Noll apresentam narradores protagonistas em situações-limite, em confronto com a morte de diferentes maneiras. As três narrativas têm em comum a suspensão de categorias, inserindo os protagonistas num espaço liminar, onde se produz discurso repleto de indeterminações. Neste artigo, procurase verificar alguns desdobramentos da presença de liminaridade e situações-limite nas narrativas, principalmente a respeito da construção do foco narrativo, afastado do discurso hegemônico, patriarcal e heteronormativo que constitui grande parte do cânone da literatura brasileira.
\end{abstract}

Palavras-chave: narrador; limiar; situação-limite; morte; ambiguidade.

Recibido: 5 de febrero de 2016

Aprobado: 5 de mayo de 2016

*Maestría en Literatura Brasileña en la Universidad de Sao Paulo (2012). Graduada en portugués-francés de la Facultad de Filosofía, Letras y Ciencias Humanas - USP. (2008).

Dirección electrónica: gabriela.nor@usp.br 


\title{
Immeasureable feelings: liminality and the narrator's point of view in contemporary Brazilian literature
}

\begin{abstract}
Rútilo nada, by Hilda Hilst, Teatro, by Bernardo Carvalho and Acenos e afagos, by João Gilberto Noll are narratives that feature narrators in limit-situations, in confrontation with death in different ways. The works analyzed place the protagonists in a threshold, from which the narrators produce speeches full of indetermination. In this article, we aim at verifying some consequences of the presence of liminality and limit-situations in the narratives, especially regarding the construction of the narrators' points of view, which are distant from the hegemonic, patriarchal and heteronormative discourse that constitutes much of the canon of Brazilian literature.
\end{abstract}

Keywords: narrator; threshold; limit-situation; death; ambiguity.

Cómo citar este artículo

APA: Ruggiero Nor, G. (2016). Sentimentos vastos: liminaridade e foco narrativo na literatura brasileira contemporânea. Poligramas, No. 42, junio. Pp., 111-125

MLA: Ruggiero Nor, Gabriela. "Sentimentos vastos: liminaridade e foco narrativo na literatura brasileira contemporânea”. Poligramas 42 (2016): pp. 111-125 Print.

Chicago: Ruggiero Nor, Gabriela. 2016. Sentimentos vastos: liminaridade e foco narrativo na literatura brasileira contemporânea. Poligramas 42 (junio): pp. 111-125 
Ao analisar a figura do narrador na literatura brasileira contemporânea, Jaime Ginzburg chama atenção para o privilégio que costumam ter aqueles narradores que reforçam o modelo patriarcal. Tal modelo "prioriza homens brancos, de classe média ou alta, adeptos de uma religião legitimada socialmente, heterossexuais, adultos e aptos a dar ordens e sustentar regras" (Ginzburg, 2012, p.200). Segundo o autor, esse paradigma pode ser encontrado exemplarmente em narrativas do século XIX, como as obras de José de Alencar, romances históricos e regionalistas, embora se mantenha como norma inclusive nos casos em que a voz narrativa não se engaja com os valores propagados pelas classes dominantes. Assim, "essa presença [do narrador], exposta ora de modo aderente, ora crítico, atua como ponto de referência para definir comportamentos e moralidades" (Ginzburg, 2012, p.200).

A partir da década de 1960, observam-se cada vez mais exemplos que fogem a essa caracterização, subvertendo o modelo que protagonizou grande parte da narrativa produzida até então. Ginzburg menciona Cristóvão Tezza, Cíntia Moscovich e Luiz Alberto Mendes, entre outros, como autores cujos narradores, oriundos de grupos marginalizados, encontram-se apartados da esfera privilegiada. Com isso, a voz narrativa assume diferentes matizes, produzindo discursos muitas vezes avessos à tradição e à historiografia oficial. Afinal, conforme lembra Paulo Sérgio Pinheiro,

O mais democrático dos Estados é sempre regime de exceção para enormes contingentes. Loucos, prostitutas, prisioneiros, negros, hispânicos, árabes, curdos, judeus, ianomâmis, aidéticos, homossexuais, travestis, crianças, operários irão nascer e morrer sem terem conhecido o comedimento do Leviatã. (2007, p. 271)

São esses contingentes que, em parte da produção brasileira atual, passam a articular a voz narrativa. As obras Rútilo nada (1993), de Hilda Hilst, Teatro (1998), de Bernardo Carvalho e Acenos e afagos (2008), de João Gilberto Noll apresentam narradores protagonistas caracterizados como outcasts, seja por serem filhos de imigrantes, homossexuais, fugitivos ou criminosos. Os personagens elencados colocam-se em posição de confronto com uma coletividade que lhes é hostil, nas franjas do discurso hegemônico, patriarcal e heteronormativo. 
No entanto, os narradores analisados não estão somente à margem: eles vêm ocupar efetivamente este entre-lugar sinalizado por sua marginalidade. Em outras palavras, trata-se de estar na própria margem, espaço que nos textos em questão deixa de ser unicamente periférico e relativo a um centro, como sugere a acepção usual do termo, para se tornar local - literal ou metafórico - de produção de discursos, deflagrador de percepções não usuais.

Notadamente, pese a longeva resistência do modelo canônico de narrador em literatura brasileira, a quebra de paradigma realista pode ser verificada, em diferentes graus de experimentação estética, desde meados do século XX. Rosenfeld (1991) e Adorno (2003) apontam em Reflexões sobre o romance moderno e Posição do narrador no romance contemporâneo, respectivamente, de que maneira autores como Proust, Kafka e Beckett, entre outros, romperam com o realismo formal. No Brasil, textos produzidos por autores como Clarice Lispector e Guimarães Rosa se alinham com as tendências mencionadas por esses dois críticos. Na literatura de Carvalho, Hilst e Noll, trata-se, contudo, de incorporar de forma radical, na construção dos narradores protagonistas, um entendimento da constituição do sujeito como necessariamente limítrofe e precária, como será detalhado ao longo deste artigo.

Os focos narrativos dos textos em exame são afins a uma interpretação do sujeito de caráter freudiano, ou seja, baseada na não soberania do eu. São personagens que descartam a configuração de um efeito de real nas narrativas que conduzem; nunca se perde de vista a ação do inconsciente sobre a memória, o discurso, os afetos. Em sua análise do psiquismo,

(...) Freud teve que enunciar que a consciência não era contínua, como estava então estabelecido no campo da filosofia do sujeito, mas descontínua. No contexto dessa descontinuidade, o inconsciente se apresentava de maneira episódica, mas constante, no campo lacunar da consciência. (...) A hipótese do inconsciente pressupunha, então, uma divisão do sujeito de caráter estrutural, pois transcenderia o campo da patologia mental e se evidenciaria na experiência psíquica normal através das formações do inconsciente. (Birman, 1997, pp.25-26)

Se as experiências psíquicas que revelam lacunas e indeterminações são parte de uma vivência normal do indivíduo, como quer Birman, 
então tais afirmações encontram eco na reflexão de Adorno a respeito do romance: para ele, se o gênero "quiser permanecer fiel à sua herança realista e dizer como realmente as coisas são, então ele precisa renunciar a um realismo que, na medida em que reproduz a fachada, apenas a auxilia na produção do engodo" (2003, p.57). Ou seja, é preciso que diferentes estratégias formais deem conta dos desafios enfrentados historicamente no momento da produção do texto literário, uma vez que "os antagonismos não resolvidos da realidade retornam às obras de arte como os problemas imanentes de sua forma" (Adorno, 1970, p. 16). Frente a essas observações iniciais, já é possível inferir que o paradigma utilizado para descrever narradores como aquele proposto por Ian Watt (1990), bem como tipologias como aquela figurada em Friedman (Leite, 1985), amplamente utilizadas em crítica literária, não respondem adequadamente à demanda analítica dos textos ora examinados. O intuito deste artigo, é, portanto, propositivo, na medida em que se busca encontrar, numa perspectiva interdisciplinar, elementos teóricos que contemplem os objetos em questão. Neste horizonte, propõe-se a articulação de dois conceitos para uma investigação preliminar dos focos narrativos das obras elencadas: a situação-limite e o limiar, os quais serão explicitados no decorrer desta análise.

O termo "situação-limite" pode ser entendido como um momento de impasse agudo, deflagrado por um evento impactante, como traumas, violência, o êxtase e a morte: circunstâncias que comunicam um excesso. Assim, cabe refletir acerca de como tal excesso é incorporado esteticamente às narrativas. Uma das possibilidades para abordar o tema é observar o par sublime e abjeto: Marcio Seligmann-Silva propõe certo paralelismo entre os dois conceitos, afirmando que

Como o sublime, também o abjeto é uma manifestação de uma ausência de limite - mas diferentemente dele, a abjeção representa esse não-limite, por assim dizer, "para baixo". Se o sublime representou no século XVIII uma categoria através da qual migraram para a estética elementos da teologia em dissolução, o abjeto, por sua vez, não aponta mais para o céu, para um excesso de significado, mas sim para o negativo pré-significado. (2005, p.40) 
Os dois conceitos remetem a uma experiência inapreensível pelos sentidos. $\mathrm{O}$ excesso veiculado pelo sublime, por designar significados absolutos, plenos, remetendo à espiritualidade, à luz, a Deus. Já o excesso do abjeto, para Kristeva, teria relação com a perda de identidade, por ser a abjeção justamente aquilo que remete o sujeito para aquém dele mesmo (Kristeva, 1980), num ponto de negatividade extrema. Nos textos literários em análise, o excesso aparece formalmente por meio de mecanismos como hipérbole, enumeração, repetição, demasiada subordinação, entre outras. Tematicamente, ele é incorporado por meio de relatos de brutal violência, pulsão sexual intensa e presença de campo lexical relativo à abjeção.

As três narrativas têm em comum o embate com a morte, um dos casos emblemáticos de situações-limite. Em Teatro, este confronto se dá através do risco iminente de o narrador morrer, a dúvida sobre a sobrevivência de um personagem, Ana C., e a abjeção do país para onde o narrador Daniel $\mathrm{I}^{1}$ foge, descrito como uma lata de lixo, um cemitério (Carvalho, 2006, p.16). Além disso, para narrar sua história, Daniel I primeiramente forja sua morte, abandonando, assim, os traços de sua vida como cidadão do "país das maravilhas", para onde seus pais migraram e onde nasceu. Em Rútilo nada, é o suicídio do amante de Lucius, protagonista, e o consequente esvaziamento e negatividade do narrador no processo de luto e rememoração que colocam a morte em cena. Já em Acenos e afagos, é o próprio narrador protagonista que, em determinado momento do texto, não sabe mais se está morto ou vivo.

A intensidade de situações-limite nas narrativas leva à suspensão de categorias habitualmente usadas para descrição e caracterização de personagens - como gênero, nome, profissão, entre outros - incidindo em profundo abalo de identidade e sugerindo, mais que nunca, que ela é sempre processual, em movimento: imperiosamente transitória. Os narradores de Carvalho, Hilst e Noll, assim, parecem incorporar a margem como elemento paradoxalmente estruturante: é no intervalo que apenas contingentemente se deixam definir, por aquilo que quase são,

\footnotetext{
${ }^{1}$ Os narradores da primeira e segunda partes do romance possuem o mesmo nome. Para diferenciá-los, será adotada a designação Daniel I (narrador de "Os sãos") e Daniel II (narrador de "O meu nome") ao longo do artigo.
} 
por aquilo que talvez sejam, que poderiam ser. Ou seja, a ambiguidade deixa de ser um substrato da interpretação para se tornar condição de leitura, ponto de partida.

Rútilo nada é exemplar para compreender a questão da identidade como dinâmica, ou seja, impermanente. Em meio a suas rememorações, Lucius afirma: "Vejo-o [Lucas] de costas agora, é sólido, crível, nada de angélico ou inefável, e um novo ou talvez um antigo e insuspeitado Lucius irrompe, dois escuros e contraditórios, aguçados e leves, violentos e sórdidos (Hilst, 2003, p.88).

As oposições entre um "antigo Lucius" e uma "tentativa de criar-se novo" são constantes ao longo da novela e indicam o desmoronamento das crenças relativas à própria identidade de Lucius, desconstrução que tem início a partir de sua descoberta como homem homossexual. O ápice do choque de subjetividade do protagonista se dá com a morte de Lucas.

Além de colocar em xeque crenças acerca de sua própria identidade, Lucius também assimila traços de Lucas, o personagem morto. A intensidade da relação afetiva entre Lucius e Lucas implica numa confluência de elementos dos dois personagens diretamente no narrador, confundindo os limites entre ele e seu amante. "Te seguindo [a Lucas] sigo apenas a mim mesmo" e "eras o meu eu" (Hilst, 2003, pp.9596) são frases que explicitam a profundidade dos laços estabelecidos entre os dois personagens, configurando uma espécie de rendição da individualidade de Lucius em favor do personagem Lucas. "Eu não sou o que sou" (Hilst, 2003, p.93), por sua vez, sinaliza um movimento dissociativo na percepção identitária de Lucius, além de reforçar a negatividade que é constante no texto.

A alternância entre o uso de pronomes ou índices de primeira e terceira pessoas verificada no discurso autorreferente de Lucius é igualmente desagregadora, bem como o uso de imagens de animais para descrever a si mesmo, como se nota nos trechos seguintes: “(...) e eu Lucius Kod neste agora me sei mais uma esquálida cadela”, à página 86, e, mais adiante,

Cães de gelo. Ou lobos de olhar formoso inundados de cio. Ou um só lobo, Lucius Kod, preso numa armadilha jamais pensada, que oco de 
si mesmo tentou criar-se novo? Cansado de sua própria escuridão tentou verter humores, refazer-se em lagos, em luz (...). (Hilst, 2003, p.91)

Ao final do texto, surge o ponto de vista de Lucas, assumindo abruptamente a parte final do relato. O texto se encerra com poemas escritos por Lucas, e sua assinatura. Em outras palavras, a voz narrativa que conclui o texto é a voz do cadáver, e não de Lucius. Este dado reforça a confusão de fronteiras entre os dois personagens e a introjeção da subjetividade de Lucas em Lucius. O paralelismo entre os nomes evidentemente reforça esta plasticidade.

Em Acenos e afagos, também se nota a transitoriedade da identidade do protagonista, através de frases como:

Sou o anônimo, alguém que pode desaparecer de pronto sem deixar lembranças

(...)

Eu deveria ser pivô de uma grande confusão mortuária. Já não sabia se me encontrava morto ou vivo.

(...)

Vesti o roupão japonês e fui para a frente do espelho do banheiro.

Eu já era outro. (Noll, 2008, p. 60, p. 83 e pp.95-96, respectivamente)

Como se pode notar, a hesitação, a metamorfose e a incerteza marcam as afirmações do narrador acerca de sua própria identidade. A indeterminação e a dúvida a seu respeito são mantidas até o final da narrativa, sem que haja resolução.

Após ser considerado morto, o protagonista de Acenos e afagos é ressuscitado por um amigo de infância, com quem passa a viver um relacionamento amoroso. Aos poucos, o narrador vai se tornando uma mulher. $\mathrm{O}$ deslocamento de gênero inclui sua metamorfose corporal, desenvolvendo características físicas femininas, como seios, menstruação, entre outros. No entanto, ele não abandona totalmente aspectos masculinos, se tornando "um ser de sexo inconcluso (...) confuso, inoperante, com uma rarefação mental digna de sua indeterminação genital"; em suma, alguém que ocupa a "experiência lacunar". Como anuncia o narrador, "entre ser homem ou mulher fico com os dois" (Noll, 2008, pp.197e 122). 
Indeterminação semelhante pode ser notada em Teatro, em relação à personagem Ana C. Apresentada na primeira parte do romance, $O s$ sãos, como uma mulher, interesse amoroso de Daniel I na juventude, a personagem retorna sob o mesmo nome - assim como o narrador na segunda parte do romance, porém desta vez caracterizada como um homem, ator de filmes pornográficos. A descrição de Ana C., apesar das claras diferenças entre as duas partes da obra, mantém um índice em comum: sua capacidade de desaparecer e reaparecer da vida dos narradores, um elemento efêmero vinculado à sua figura, que faz do personagem uma presença fantasmática no romance. Em determinado momento da narrativa, Ana C. desaparece definitivamente, e a dúvida incide não somente em saber se o personagem está vivo ou morto, mas também em saber se ele realmente existiu (Carvalho, 2006, pp.128129).

As declarações do narrador de Acenos e afagos, bem como a composição enigmática do personagem Ana C. em Teatro e a subjetividade permeável de Lucius em Rútilo nada reforçam a ideia de margem na narrativa, por aludirem a um limite decisivo que, apesar de figurado, não chega a ser atingido de forma conclusiva - a morte, a mudança de gênero, entre outros. Afinal, as constantes dúvidas dos protagonistas acerca de quem são e de sua condição - homem, mulher, vivo, morto, louco, são - denotam um enfoque no processo de transformação, e não num resultado totalizante que daria sentido unívoco às identidades dos narradores. Nem do lado de cá nem de lá, portanto, não é a fronteira que se cruza nas narrativas, mas a margem que é ocupada: o limiar, ou seja, o entremeio, a passagem que não se concretiza plenamente.

Jeanne-Marie Gagnebin, ao discorrer acerca do limiar na obra de Walter Benjamin, atenta para a dificuldade enfrentada na tradução, para língua portuguesa, do termo em alemão Schwelle, comumente equiparado à fronteira (Grenze). Uma das hipóteses para traduções imprecisas, segundo a autora, é a semelhança fonética entre os termos latinos limitares e liminares, que pode justificar o entendimento de limite e limiar quase como sinônimos. No entanto, reforça a autora, tratam-se de duas ideias diferentes (Gagnebin, 2014, p.37). 
Os limites servem para separar, categorizar. Auxiliam o pensamento filosófico e a reflexão, impedindo que os conceitos transbordem de um local ao outro: organizam, dividem, mantêm ideias diferentes em locais definidos. Assim, eles determinam aquilo que faz parte de um conjunto, por exemplo, e aquilo que já deve ser considerado como pertencente a outro.

O conceito de limiar, por sua vez, compreende um espaço e um tempo que é antes de tudo uma zona, um local de trânsito. E, diferentemente do limite, ele não está lá para determinar, mas seu contrário: trata-se de um espaço de indeterminação, por indicar travessia. A margem, enquanto espaço latente, é limiar antes de tocar na fronteira.

Walter Benjamim, em Passagens, descreve-o da seguinte maneira:

Ritos de passagem - assim se denomina no folclore as cerimônias ligadas à morte, ao nascimento, ao casamento, à puberdade etc. Na vida moderna, estas transições tornam-se cada vez mais irreconhecíveis e difíceis de vivenciar. Tornamo-nos muito pobres em experiências liminares. $\mathrm{O}$ adormecer talvez seja a única delas que nos restou. (E, com isso também, o despertar). (...) O limiar é uma zona. Mudança, transição, fluxo estão contidos na palavra schwellen [inchar, intumescer], e a etimologia não deve negligenciar estes significados. Por outro lado, é necessário determinar (manter, constatar) o contexto tectônico e cerimonial imediato que deu à palavra seu significado. Morada do sonho. (2009, p.535)

Em antropologia, o termo é utilizado para descrever as zonas atravessadas pelos indivíduos em transe durante um ritual. Entra-se de uma forma no rito, mas não se sai dele da mesma maneira. Mary Douglas, em Pureza e perigo, articula a travessia do limiar em rituais com as passagens e transições mundanas e corriqueiras. Afirma ela que:

Van Gennep mostrou como os limiares simbolizam o início de novos estatutos. Por que é que o noivo toma a noiva nos braços para transpor a porta de casa? Porque o degrau, a trave e as ombreiras da porta constituem um quadro que é condição necessária e quotidiana da entrada em casa. Passar por uma porta é um ato banal, mas que pode significar muitas maneiras diferentes de entrar. $\mathrm{O}$ mesmo é válido para os cruzamentos dos caminhos, as arcadas, as novas estações, as novas roupas etc. Nenhuma experiência é demasiado banal para ser 
integrada num rito ou possuir uma significação que a ultrapassa. Quanto mais pessoal e íntima for a fonte do simbolismo ritual mais eloquente será a sua mensagem. Quanto mais o símbolo for colhido no fundo comum da experiência humana, melhor será recebido e mais conhecido será. (1991, p.86)

Há diversas sinalizações de passagens e transições nas obras analisadas. Desde os funerais de Lucas e do narrador de Noll, ritos propriamente ditos, à morte forjada de Daniel I em Teatro. O trânsito entre fronteiras do protagonista de Carvalho também se relaciona com este tema. Embora fisicamente se concretize a passagem - Daniel I chega ao outro lado - a passagem simbólica não acompanha o deslocamento físico, ou seja, ele continua vinculado à sua vivência no país das maravilhas e não se reconhece como pertencente ao país de seus pais. Mesmo adotando a língua originária de sua família como suporte para seu relato, Daniel I não consegue compreender expressões neste idioma, exprimindo uma falta, uma lacuna que impede seu reconhecimento como um cidadão do país originário de sua família.

A transição de um estado para o outro - que pode ser de purificação ou mudança de status, para citar alguns casos (Turner, 1974) - é um momento de intervalo, em que o sujeito, temporariamente detido na passagem, não concluiu sua metamorfose. Dessa forma, a progressão interna do ritual implica na existência de uma zona intermediária anterior à conclusão do rito. Justamente por esta qualidade de estar no meio, entre dois estados específicos, a identidade do participante se mantém incerta e indefinível durante o ritual. A articulação com esses elementos que dizem respeito à antropologia é afim ao curso seguido pelos personagens das narrativas estudadas, que incluem até mesmo vocabulário aderente a esse campo de pesquisa. Podem ser encontradas, por exemplo, no romance de Noll, diversas referências ao desejo e à excitação sexual como momentos de transe, algumas delas compiladas em seguida:

(...) ninguém se dava conta se era um disparate ou simplesmente uma iniciação ao transe (...) 
Vinha-me então esse gosto condenado na boca, gerando mais e mais excitação, o transe até.

(...) cinco ou seis rapazes se postavam aparentemente à nossa espera, para iniciarem algum rito (...)

(...) meu amigo doava à seita novamente uma ereção faltando pouco para ser completa (...)

Ao atingir no entanto essa fronteira avançada do gozo feminino, percebia que o transe era pouco, eu queria mais. (Noll, 2008, p.9, pp.1011, p. 24, p. 27 e p.144, respectivamente)

A profusão de expressões que remetem ao transe ritual e religioso, em remissão a estados alterados de consciência, reforça o registro da desmedida e do desregramento, privilegiados no romance. É possível compreender a morte do narrador de Noll como um ápice do excesso, seu esgotamento e exaustão, para que posteriormente o protagonista possa ressurgir numa vivência inédita, insólita, ressignificando-se como (quase) mulher ao lado do amigo - marido - engenheiro. Além disso, se a morte é uma saída do mundo e opera num registro além do Logos (Dumoulié, 2007, p.13), então o aniquilamento do narrador pode ser lido também como sua saída definitiva do mundo organizado. Afinal, sua morte é acompanhada pelo abandono de sua vida familiar, a renúncia ao trabalho e ao dinheiro. Nenhuma categoria serve mais para descrevê-lo, nem a mais primária - morto ou vivo? - justamente porque o protagonista vai passar a viver num excesso marginal, porém integralmente.

Nas três obras, o desvio dos protagonistas para o sexo, a fuga e a metamorfose indica um abandono do pragmatismo em favor da abstração - movimento de renúncia da medida, em direção à desmedida. É assim em Rútilo nada quando Lucius indefere seu local de pai, originário de uma família conservadora, para se aproximar de Lucas e, posteriormente à sua morte, se transfigurar, por dor e melancolia, na "morte e não a vida (...) musgos finos pendendo dos abismos" (Hilst, 2003, p.86). Em Teatro, Daniel I passa de "um cidadão como todos os outros", confiável, alguém que "estava integrado" na polícia, porque o "tratavam como a um igual", a um "monstro" (Carvalho, 2006, p.15 e p.13), fugindo da própria polícia que o acolhera e de que fazia parte. Já Daniel II, um "fotógrafo de paisagens", acaba sendo internado, considerado louco por 
acreditar na existência e na sobrevivência de Ana C. No romance de Noll, o narrador abandona sua esposa e seu filho, seu trabalho e sua casa, e, radicalmente, a própria vida, para se transmutar em mulher ao lado de seu amante. No entanto, como persistem resíduos das vivências anteriores dos protagonistas, essa travessia à desmedida não ocorre de maneira plena, mas com interferências e dúvidas, de modo descontínuo.

Quando Gagnebin (2014), comenta acerca do limiar, atém-se principalmente ao espaço. Nas obras analisadas, é como se os narradores incorporassem tal configuração espacial à sua própria constituição. Narram, assim, a partir da desrazão, não da loucura ou da sanidade; da indistinção, de uma condição que não é propriamente a morte nem a vida, mas um intermédio desconfortável. Com isso, pode-se dizer que as narrativas em questão são antíteses dos Bildungsroman: em vez do processo de amadurecimento, com diversas superações ao longo do romance, finalizado com o efeito de completude e totalidade, o que se nota nas obras é a dilapidação, o crescente desconhecimento dos protagonistas, progressivamente incógnitos e ambíguos conforme o enredo avança. A cronologia de uma vida é desarranjada em farrapos de memória que irrompem nos textos, favorecendo uma abordagem psicanalítica da rememoração e da percepção temporal.

Como se pode notar, procurou-se passar do exemplo mais sutil àquele mais explícito, no tocante à relação entre as situações-limite e o foco narrativo. Na prosa de Hilda Hilst, observou-se a diluição parcial de elementos do personagem morto, Lucas, na figura de Lucius, protagonista. Ademais, atentou-se para a alternância das vozes narrativas na obra, cujas páginas finais são sustentadas pelo ponto de vista de Lucas - ou seja, do cadáver, terminando o texto com extrema negatividade. As situações-limite em Rútilo nada estão relacionadas à morte, à violência $\mathrm{e}$ à perturbação na identidade de Lucius, tanto pelos eventos mencionados, quanto pela própria descoberta de sua homossexualidade. Em Teatro, de Carvalho, inúmeras mortes provocadas por ataques terroristas e a travessia de Daniel I para o país de seus genitores desestabilizam o protagonista de Os sãos, que anuncia sua própria morte ao final da primeira parte do romance. Em O meu nome, a possibilidade de Daniel II estar louco e a multiplicação de dúvidas sobre Ana C. culminam na 
internação do narrador em uma instituição psiquiátrica. Já em Acenos e afagos, o protagonista, ambivalente e na incerteza entre estar vivo ou morto, narra sua metamorfose incompleta em mulher.

Um dos desafios é analisar e entender o discurso que contempla adequadamente as exigências deste lugar limítrofe. Há de ser, pela observação das obras discutidas, um discurso de profunda crítica à função referencial da linguagem, que privilegia versões conflitantes, diluição do tempo narrativo. As narrativas colocam em questão o primado da linguagem, apresentando narradores para os quais os discursos alheios parecem sempre cifrados e lacunares, e que tampouco conseguem se fazer compreender. Notadamente, tal construção só é possível através da renúncia discursiva a pressupostos cartesianos com relação à comunicação - ou seja, a expectativa de que não haja ruído na interlocução, de que o que se diz é aquilo que se entende. A escassez de diálogos nas obras e a precariedade dos mesmos quando eles existem indica deslocamento em direção ao silêncio: menos verbalização, menos representação, o reconhecimento de que a linguagem só pode chegar perto de seus objetos, nunca descrevê-los por completo. Ou, conforme enuncia Lucius, "Os sentimentos vastos não têm nome" (Hilst, 2003, p.85). 
Poligramas 42 - junio de 2016

\section{Referências bibliográficas:}

Obras literárias:

Carvalho, B. (2006). Teatro. São Paulo: Companhia das Letras.

Hilst, H. (2003). "Rútilo nada”. Rútilos. São Paulo: Globo.

Noll, J.G. (2008). Acenos e afagos. Rio de Janeiro: Record.

Obras teóricas e críticas:

Adorno, T.W. (2003). Posição do narrador no romance contemporâneo. Em Notas de literatura I. São Paulo: Ed.34.

Adorno, T.W. (1970). Teoria Estética. Lisboa: Edições 70.

Benjamin, W. (2009). Passagens. Belo Horizonte: Ed. UFMG.

Birman, J. (1997). Estilo e modernidade em psicanálise. São Paulo, Ed.34.

Douglas, M. (1991). Pureza e perigo. São Paulo: Perspectiva.

Dumoulié, C. M. (2007). Tudo o que é excessivo é insignificante. Tempo Brasileiro, no. 169. Rio de Janeiro.

Gagnebin, J-M. (2014). Limiar, aura e rememoração. São Paulo. Ed.34.

Ginzburg, J. (2012). O narrador na literatura brasileira contemporânea. Tintas, Quaderni di letterature iberiche e iberoamericane, no. 2.

Kristeva, J. (1980). Pouvoirs de l'horreur. Paris: Seuil.

Leite, L.C. (1985). O foco narrativo ou a polêmica em torno da ilusão. São Paulo: Ática.

Pinheiro, P.S. (2007). Estado e Terror. In.: Novaes, A. (org.). Ética. São Paulo, Companhia das Letras.

Rosenfeld, A. (1991). Reflexões sobre o romance moderno. En Texto/contexto. São Paulo: Perspectiva.

Seligmann-Silva, M. (2005). O local da diferença. São Paulo, Ed.34. 